\title{
ERRATUM
}

Open Access

\section{Erratum to: Zn (II) and Cu (II) adsorption and retention onto iron oxyhydroxide nanoparticles: effects of particle aggregation and salinity}

Rebecca B. Chesne and Christopher S. Kim*

\section{Erratum to: Geochemical Transactions (2014) 15:6 DOI 10.1186/1467-4866-15-6}

In the original version of this article errors in Figs. 5 and 9 were identified by the authors. The corrected figures are given below.

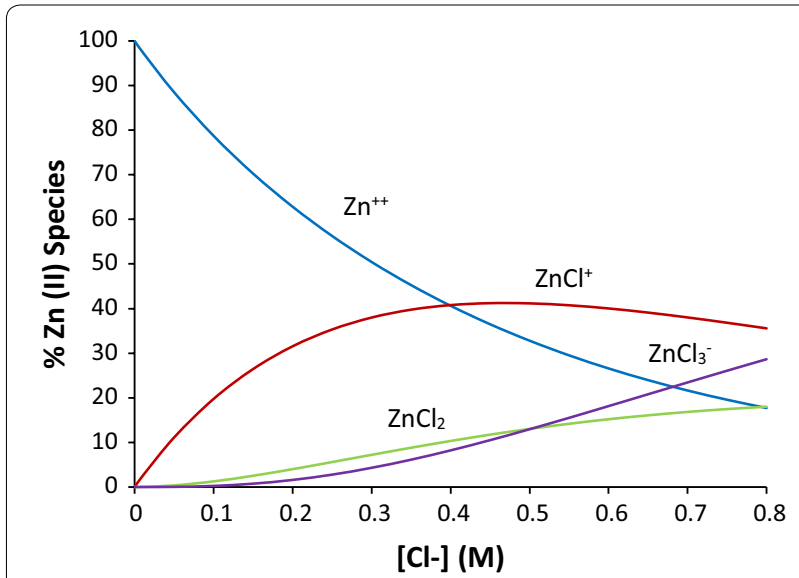

Fig. 5 Speciation diagram of $Z N(I I)$ chloride species at a range of chloride concentrations and a $\mathrm{Zn}(\mathrm{II})$ concentration of $0.046 \mathrm{mM}$ at $\mathrm{pH} 5.0$

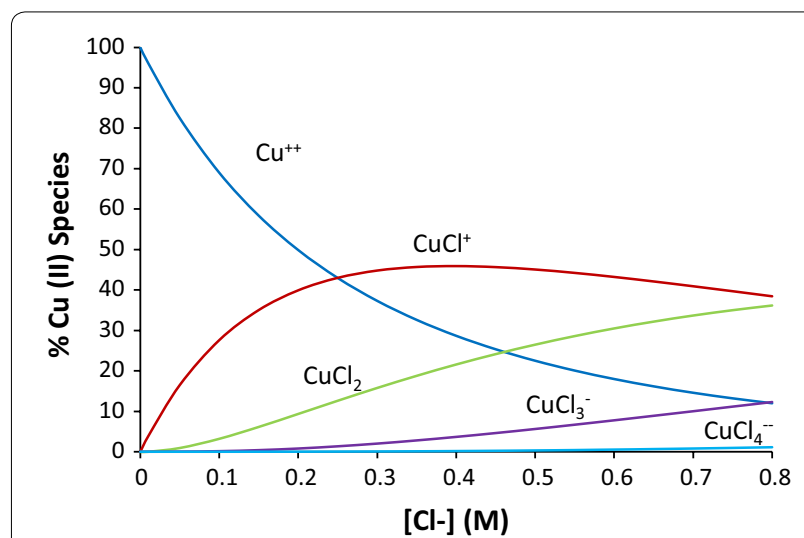

Fig. 9 Speciation diagram of $\mathrm{Cu}(\mathrm{II})$ chloride species at a range of chloride concentrations and a Cu(II) concentration of $0.131 \mathrm{mM}$ and $\mathrm{pH} 5.0$

The online version of the original article can be found under doi:10.1186/1467-4866-15-6.

Received: 2 October 2015 Accepted: 2 October 2015

Published online: 19 November 2015 